\title{
A Comprehensive Flexural Analysis for Sustainable Concrete Structure Reinforced by Embedded Parts
}

\author{
Yuantian Sun $\mathbb{D}^{1,},{ }^{1,2}$ Junfei Zhang, ${ }^{3}$ Yunchao Tang $\mathbb{D},{ }^{4}$ \\ Yufei Wang, ${ }^{5}$ Junbo Sun $\mathbb{D D}^{6,7}$ and Xiangyu Wang ${ }^{7}$ \\ ${ }^{1}$ Ningbo Zhongchun High Tech Co., Ltd., Ningbo 315100, China \\ ${ }^{2}$ School of Mines, Key Laboratory of Deep Coal Resource Mining of the Ministry of Education, \\ China University of Mining and Technology, Xuzhou, Jiangsu 221116, China \\ ${ }^{3}$ School of Civil and Transportation Engineering, Hebei University of Technology, 5340 Xiping Road, Beichen District, \\ Tianjin 300401, China \\ ${ }^{4}$ College of Urban and Rural Construction, Zhongkai University of Agriculture and Engineering, Guangzhou 510225, China \\ ${ }^{5}$ Chongqing University Industrial Technology Research Institute, Chongqing University, Chongqing 400045, China \\ ${ }^{6}$ Institute for Smart City of Chongqing University in Liyang, Chongqing University, Chongqing, Jiangsu 213300, China \\ ${ }^{7}$ School of Design and Built Environment, Curtin University, Perth, WA 6102, Australia \\ Correspondence should be addressed to Junbo Sun; junbo.sun@curtin.edu.au
}

Received 28 August 2021; Accepted 3 November 2021; Published 23 November 2021

Academic Editor: Wenjie Ge

Copyright (C) 2021 Yuantian Sun et al. This is an open access article distributed under the Creative Commons Attribution License, which permits unrestricted use, distribution, and reproduction in any medium, provided the original work is properly cited.

\begin{abstract}
In this research, the plate embedded parts and grooved embedded parts reinforced concrete structures were investigated. Two types of plate embedded parts and three types of grooved embedded parts experienced coating treatment to enable sustainable function. Later, the ultimate failure capacity by bending experiments was conducted and compared with the theoretically calculated results. Moreover, three grooved embedded parts were simulated by ABAQUS to compare the results with the experimental exploration results, which was in close agreement with the theoretically calculated results and finite element analysis results. The result indicated that the failure modes of the embedded specimens under the five working conditions are all concrete vertebral failure. The plate-type embedded components were proved to exhibit higher ultimate bearing capacity than the grooved embedded parts. Moreover, the flexural and shear capacity of these five types of embedded parts has not been fully developed. The ultimate flexural and shear capacity of these five types of embedded parts could be further explored by adjusting the higher concrete grade.
\end{abstract}

\section{Introduction}

As the construction industry develops rapidly, the mechanical properties of the concrete have attached more attention $[1,2]$. Consequently, the reinforced concrete (RC) structures have been widely used in constructions with the advantages of high sustainability, excellent mechanical strength, and considerable deformability resistance $[3,4]$. However, the ordinary RC structures cannot meet the increasing demand of engineering specifically for the formworks in structure nodes [5-7]. This phenomenon points to the need for novel RC structures for filling structure nodes' formworks and producing high-quality constructions [8].

The application of sustainable embedded parts in steelconcrete composite structure joints has been used extensively as a promising material [9]. The embedded parts' structure comprising Halfen channel embedded parts and plate embedded parts are raising attention and can be the feasible solutions towards current drawbacks [10]. The embedded parts' structures do not depend on the secondary construction of the ground in constructions with the advantages of the convenient assembly procedure, low cost, and labor [11]. Stout et al. [12] patented a method for making 
cast-in-place concrete structures to reveal integrally bounded confines in the structure. Stout et al. [13] also explored a void-creating device to be embedded in a concrete structure, aiming at defining a labyrinth of passageways with the concrete structure, which revealed the passage procedure for service parts through the interior parts within the concrete.

At present, drawing, shearing, and seismic resistance are major concerns for embedded parts worldwide. In engineering application, the slot embedded parts, bearing the bending force and shear force in most cases as the joint of the steel-concrete structure [14]. However, few studies have been conducted on the bending-shear test performance of slot embedded parts. Moreover, despite the embedded parts being widely used, there are few standard designs for slot embedded parts.

In this study, a novel coating treatment was conducted upon three kinds of HALFEN channel embedded parts and two kinds of plate embedded parts to reveal the sustainable function. The bending-shear experiments were carried out with different specifications to analyze the ultimate bearing capacity and failure modes. Under the actual test conditions, the theoretical calculation and finite element analysis using ABAQUS were carried out on the flexural and shear test to determine the reliability of the HALFEN channel embedded parts in the practical application. The study can be regarded as a guideline in this research area.

\section{Experimental Study}

2.1. Experimental Design. 15 specimens for two types of embedded parts were analyzed comprising A-1, A-2, B-1, B-2, and B-3. The A group was the structure reinforced by embedded plate and the $\mathrm{B}$ group means the grooved embedded parts corresponded to three different types of grooved embedded parts. Each batch contains three samples and the loading configurations are constant. Specifically, A-1 and A-2 were each reinforced by a $150 \mathrm{~mm} \times 150 \mathrm{~mm} \times 10 \mathrm{~mm}$ and a $150 \mathrm{~mm} \times 150 \mathrm{~mm} \times 20 \mathrm{~mm}$ anchor plate separately. Meanwhile, the embedded plate was welded by 4 steel bar anchor legs $(200 \mathrm{~mm}$ in length and $20 \mathrm{~mm}$ in diameter) and the anchor legs were also welded to an I-beam $(150 \mathrm{~mm})$ with different distances towards edges $(10 \mathrm{~mm}$ for $\mathrm{A}-1$ and $20 \mathrm{~mm}$ for A-2). For the B group, the specimen was reinforced by HALFEN groove $(40 \mathrm{~mm}$ width and $22 \mathrm{~mm}$ height for B-1, $50 \mathrm{~mm}$ width and $30 \mathrm{~mm}$ height for B-2, and $52 \mathrm{~mm}$ width and $34 \mathrm{~mm}$ height for B-3). The groove was weld by 4 anchor legs with a length of $100 \mathrm{~mm}$ (overall length of $300 \mathrm{~mm}$ ). The anchor legs were linked with $5 \mathrm{~T}$ bolts on the other side.

The concrete specimen sizes were $450 \mathrm{~mm} \times 450 \mathrm{~mm} \times 450 \mathrm{~mm}$ (A group) and $600 \mathrm{~mm} \times 400 \mathrm{~mm} \times 300 \mathrm{~mm}$ (B group). The design strength of all specimens was C30 and the embedded parts were Q345-type galvanized steel. The surface of the anchor plate was even with the concrete, embedding all anchor legs. The bending or shearing loads were applied to the I beam or $T$ bolt, and the loading eccentricity was $40 \mathrm{~mm}$ from the anchor plate plane. The specimen parameters were demonstrated in Table 1.
2.2. Sustainable Treatment. All designed embedded parts experienced coating treatment to guarantee sufficient sustainability in-service lifespan. A self-developed $\mathrm{Zn}-\mathrm{A} 1-\mathrm{Mg}$ $\mathrm{RE}$ alloy on a small scale is utilized coating, as shown in Figure 1. This is because the alloy not only exhibits outstanding corrosion resistance but also fills the microcracks in the coating which enhances the mechanical performance. First, pure Zn strip at the content of $99.9 \%$ is sprayed onto the surface of embedded parts as a base by a high-velocity spraying gun (HAS-02) cooperated by a CDM system (AS3000) at $200 \mu \mathrm{m}$ thickness. Later, the Zn-A1-Mg alloys are coated upon the surface of the embedded part with a thickness of $400 \mu \mathrm{m}$. The spraying current stands at $140 \mathrm{~A}$, and spraying voltage employs $30 \mathrm{~V}$. The spraying distance keeps at $250 \mathrm{~mm}$ and the air pressure is $0.65 \mathrm{MPa}$.

2.3. Loading Parameters. The 500t servo compression-testing machine is utilized to load the test specimens. Meanwhile, a self-control device is set on the upside of the specimen to prevent the sliding effect on the workbench. The structure diagram of the entire loading system and selfcontrol device are, respectively, shown in Figure 2.

As for the loading procedure, the servo machine first utilized a $0.2 \mathrm{kN} / \mathrm{s}$ preload rate till the $10 \%$ yield load followed by a recovering process. After the inspection of the loading device and instrument, the servo machine applied uniaxial load at a rate of $0.4 \mathrm{kN} / \mathrm{s}$ with $50 \mathrm{~mm}$ eccentricity until failure. The loading value, as well as the strain data, was collected automatically by the servo machine and the static strain tester. Especially, both the circumscribed I-beam of plate-type and the circumscribed T-type bolt of slot-type built-in fitting obtained 4 anchor legs using 8 wires to connect with the static strain tester during loading. The loading procedure of plate-type built-in fitting and slot-type built-in fitting separately are illustrated in Figure 3.

\section{Test Results}

3.1. Mechanical Properties. The experimental results are shown in Figure 4 . The average failure load of A-1 was $378.73 \mathrm{kN}$ and was $78 \mathrm{kN}$ higher than that of A-2 $(299.93 \mathrm{kN})$. The mean loading capacities for the B batch were $89.76 \mathrm{kN}$ for the B-1 sample, $125.34 \mathrm{kN}$ for the B-2 sample, and $105.63 \mathrm{kN}$ for the B-3 sample.

3.2. Failure Mode. The failure modes and surface cracks for all five embedded specimens are denoted in Figure 5.

All the specimens were damaged by the concrete vertebral body with considerable cracks. For the embedded structures, the concrete around the groove began to crack slightly and then gradually expanded. After a specific threshold ( $98 \mathrm{kN}$ for B-1 and $92 \mathrm{kN}$ for B-2), the cracks on the original extend rapidly and terminally came into failure. Major cracks in the vertical direction on both sides of the middle groove steel were found, the bottom joint was protruded around the T-bolt and the upper part was pulled out due to the exerted force on the edge. 
TABLE 1: Specimen parameters for A and B groups.

\begin{tabular}{lcccc}
\hline Group & Built-in type & Anchor number and size & Sample size $(\mathrm{mm})$ & Circumscribed device \\
\hline A-1 & Plate-type & $4 * 100 * 20$ & $450 \times 450 \times 450$ & No. 14 I-beam \\
A-2 & Plate-type & $4 * 100 * 20$ & $450 \times 450 \times 450$ & No. 14 I-beam \\
B-1 & Slot-type & $4 * 100 * 20$ & $600 \times 400 \times 300$ & 5 T-type bolts \\
B-2 & Slot-type & $4 * 100 * 20$ & $600 \times 400 \times 300$ & 5 T-type bolts \\
B-3 & Slot-type & $4 * 100 * 20$ & $600 \times 400 \times 300$ & 5 T-type bolts \\
\hline
\end{tabular}

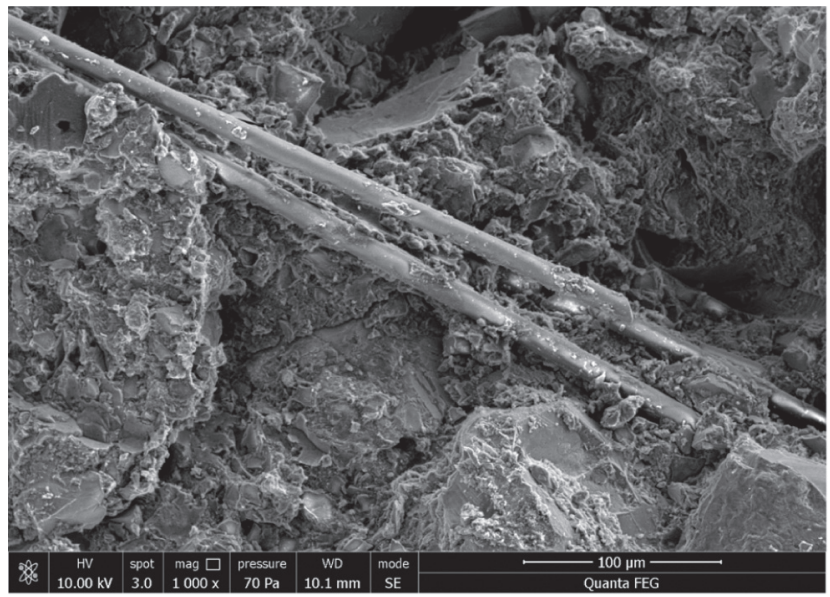

Figure 1: Microscale set up of Zn-AI-Mg-RE coating.

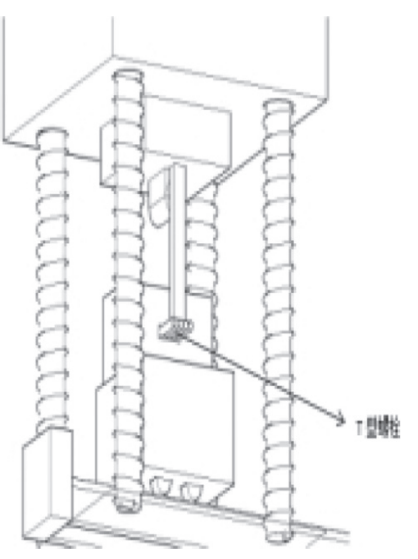

(a)

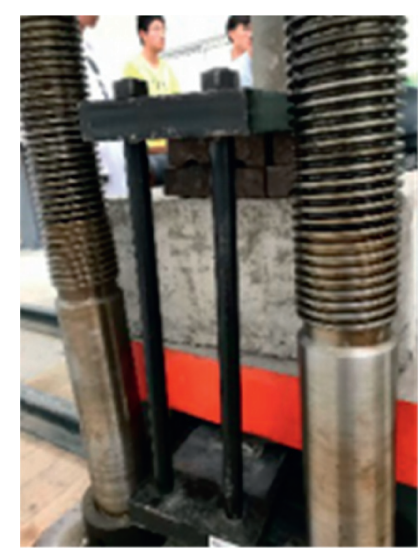

(b)

Figure 2: (a) Servo testing machine structure diagram. (b) Self-control experiment device.

\section{Theoretical Calculations}

The bearing capacity of a section of embedded components is calculated according to CEN/TS 1992-4-3:2009 [15].

\subsection{Design Calculation and Analysis of Plate Embedded Parts.} As for the damage characteristics, when the force moment $e / z$ is less than 0.3 , the embedded parts are first crushed by concrete with general shear-bearing embedded parts. When the force moment $e / z$ is more than 0.6 , the embedded parts are all damaged by the pulled anchor leg. Otherwise, the embedded part failure is caused by the compound effect of crushed concrete or the pulled anchor leg. In this study, the eccentricity is $40 \mathrm{~mm}$, and the vertical distance $Z$ between the anchor legs is $130 \mathrm{~mm}$. Therefore, the moment equals 0.3 and the theoretical damage characteristic ought to be a crushing effect to form vertebral body damage, which is consistent with the actual damage characteristics.

According to the experimental study and theoretical analysis of uniformly arranged bending-shear embedded parts with straight anchor legs, the strength of bending-shear embedded parts can be calculated according to the following equation $[16,17]$ : 


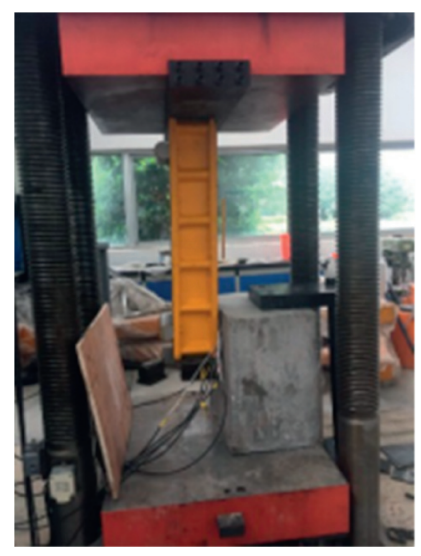

(a)

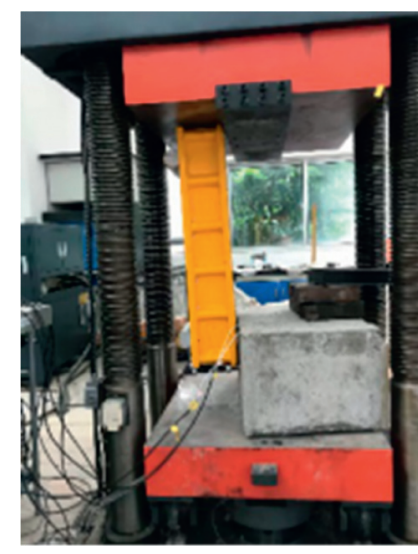

(b)

Figure 3: The built-in fitting for (a) plate-type and (b) slot-type.

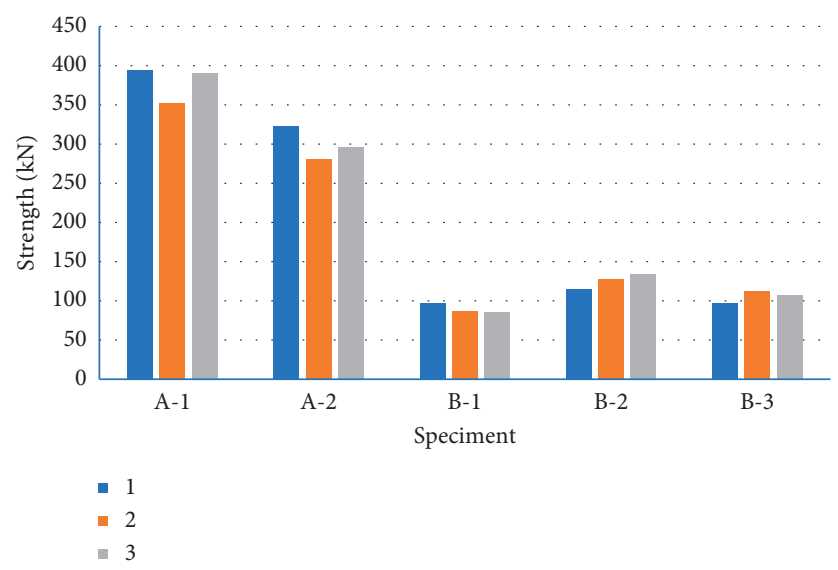

Figure 4: Experimental results of plate and groove embedded parts.

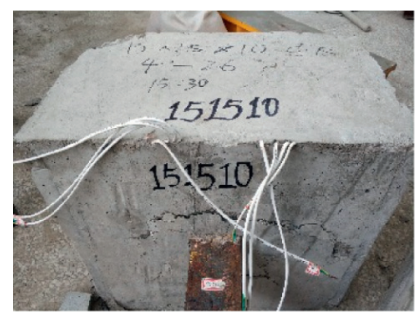

(a)

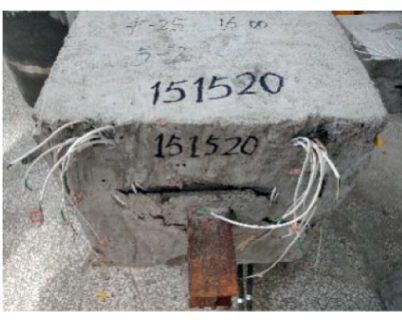

(b)

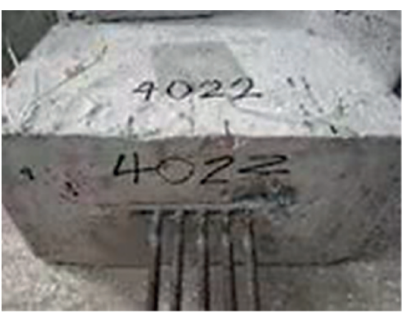

(c)

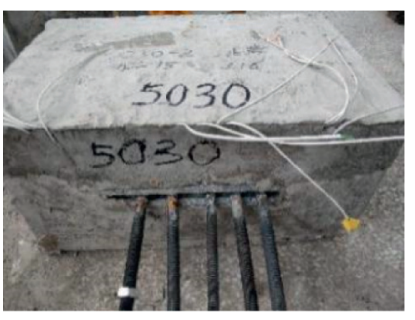

(d)

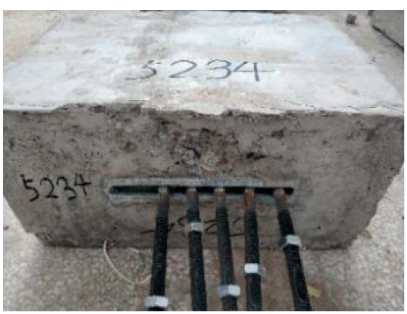

(e)

FIgURe 5: Specimen failure form for (a) A-1, (b) A-2, (c) B-1, (d) B-2, and (e) B-3. 


$$
\frac{V}{V_{u_{0}}}+\frac{0.3 M}{M u 0}=1
$$

where $V / V_{u 0} \geq 0.7$, or $(e / z) \leq 0.57\left(\alpha_{a} \alpha_{b} / \alpha_{v}\right)$.

According to the reliability analysis of embedded parts, the shear strength of embedded parts can be calculated according to equation (2) and the bending strength of embedded parts can be calculated according to equations (3) to (5):

$$
\begin{aligned}
v_{u 0} & =\alpha_{v} \alpha_{r} f_{y} A_{s}, \\
M_{u 0} & =0.4 \alpha_{a} \alpha_{b} \alpha_{r} f y A s z, \\
\alpha_{v} & =(4-0.08 d) \sqrt{\frac{f_{c}}{f_{y}}} \leq 0.7, \\
\alpha_{a} & =\frac{l_{a}^{\prime}}{l_{a}}
\end{aligned}
$$

where $\alpha_{v}$ symbols the shear strength coefficient of anchor legs, $f_{c}$ is the design value of concrete compressive strength, $f_{y}$ equals the design value of tensile strength of embedded anchor legs, $d$ is the diameter of steel bars, $\alpha_{r}$ means the influence coefficient of the number of anchor legs, $A_{s}$ is the section area for all anchor legs, $\alpha_{a}$ symbols the reduction coefficient of anchor length, $\alpha_{b}$ is the reduction factor of bending deformation of anchor plate which generally equals $1, l_{a}^{\prime}$ is the actual length of the anchor leg (200), and $l_{a}$ means the anchorage length (600) of tensile anchor legs is usually selected and calculated according to Table 2.

By combining the listed formulas, equation (6) is obtained shown as follows:

$$
\frac{V}{\alpha_{v} \alpha_{r} f_{y} A_{s}}+\frac{M}{1.3 \alpha_{a} \alpha_{b} \alpha_{r} f_{y} A_{s} z}=1
$$

As the embedded parts met the structural requirements and the anchor plate can be considered as nonbending deformation, $\alpha_{b}$ thus equals 1 . The embedded parts are equipped with two rows of anchor legs, and $\alpha_{r}$ is taken as 1 . The design value of compressive strength of concrete specimens is $14.3 \mathrm{~N} / \mathrm{mm}^{2}$, and the design value of tensile strength of embedded anchor legs is $310 \mathrm{~N} / \mathrm{mm}^{2}$.

As a result, $\alpha_{a}=1 / 3$ and the shear strength coefficient of anchor legs $\alpha_{v}$ is 0.52 . The theoretical calculation solution $\mathrm{V}$ is $148 \mathrm{kN}$, which is far lower than the experimental results of A-1 and A-2, meeting the safety considerations.

\subsection{Practical Calculation and Analysis of Groove Embedded} Parts. The embedded depth of the anchor leg was shallow, which is less than $150 \mathrm{~mm}$. The failure form of the groove embedded structure was usually concrete cone failure, and the experimental results verified this assumption. According to CEN/TS 1992-4-3:2009 [15], the formula of a failure bearing capacity of the concrete cone is described as $[18,19]$

$$
N_{R k, c}=N_{R k, c}^{0} \times \alpha_{s, N} \times \alpha_{e, N} \times \alpha_{c, N} \times \varphi_{r e, N} \times \varphi_{u c r, N},
$$

TABLE 2: The formula for calculating anchorage length.

\begin{tabular}{lcccc}
\hline \multirow{2}{*}{ Type of reinforcement } & \multicolumn{5}{c}{ Strength grade of concrete } \\
& C15 (d) & C20 (d) & C25 (d) & $\geq$ C30 \\
\hline Crescent rebar & 50 & 40 & 35 & $30 \mathrm{~d}$ \\
\hline
\end{tabular}

where $N_{R k, c}$ is the failure capacity of the concrete cone when a single anchor leg of groove-type embedded part is applied, $\alpha_{s, N}, \alpha_{e, N}$, and $\alpha_{c, N}$ are the adjacent anchor correction coefficient, boundary effect correction coefficient, and corner effect correction coefficient, respectively, and $\varphi_{u c r, N}$ is the cracking correction coefficient of concrete, and when noncracking concrete equals to1.4, $\varphi_{r e, N}$ is the shadow of bearing capacity considering the peeling of surface concrete. The formula for calculating the response coefficient is expressed in equation (8). $N_{R k, c}^{0}$ means the standard value of bearing capacity of concrete cone failure reinforced by single anchor legs of groove embedded parts under tension which is calculated as equation (9):

$$
\begin{aligned}
& \phi_{r e, N}=0.5+\frac{h_{e f}}{200} \leq 1, \\
& N_{R k, c}^{0}=8.5 \times \alpha_{c h} \times \sqrt{f_{c k, \text { cube }}} \times h_{e f}^{1.5},
\end{aligned}
$$

where $\alpha_{c h}$ is the correction factor of channel steel to concrete cone less than $1, f_{c k \text {,cube }}$ is the standard value of compressive strength of concrete cube $\left(\mathrm{N} / \mathrm{mm}^{2}\right)$, and $h_{e f}$ is the length of anchor leg of groove embedded parts.

According to the listed formulas, $h_{e f}$ is $100 \mathrm{~mm}$, and $\varphi_{r e, N}$ is thus calculated as 1 . When the specimen is C30, $f_{c k \text {,cube }}$ take $34.9 \mathrm{~N} / \mathrm{mm}^{2}$ and $\alpha_{c h}$ was chosen as 1 ; then, $N_{R k, c}^{0}$ is calculated as $50.2 \mathrm{kN}$. The adjacent anchor repair coefficient, boundary effect repair coefficient, and corner effect repair coefficient $\alpha_{s, N}, \alpha_{e, N}$, and $\alpha_{c, N}$, are $1,1.1$, and 1.2 , respectively, according to the actual situation. The concrete is noncracking concrete, and $\varphi_{u c r, N}$ is 1.4. As a result, $N_{R k, c}$ is calculated as $102.1 \mathrm{kN}$, which is in close agreement with the experimental values.

\section{Finite Element Simulation Analysis of Groove Embedded Parts Test}

\subsection{Establishment of the Finite Element Model for Slot Embedded Parts}

5.1.1. Selection of Materials. The groove embedded components (B-1, B-2, and B-3) were simulated in finite element analysis consisting of steel plate, groove embedded parts, and concrete structure. The T-type bolt is simplified as a steel plate in modeling as its main function was to transmit force to embedded parts. The steel Poisson's ratio was 0.274 , and the elastic modulus was $2.06 * 10^{3} \mathrm{MPa}$.

There were three constitutive models of concrete which are provided in ABAQUS including the brittle cracking model, dispersive cracking model, and damageplasticity model $[20,21]$. The plastic damage model of concrete is adopted in this paper because it was able to simulate the mechanical behavior of concrete under 
monotonous, reciprocating, and dynamic loads under low hydrostatic pressure and has good convergence. As for the uniaxial constitutive relationship of concrete, it was based on the damage-plasticity mode and consisted of the elastic section, strengthening section, and softening section. Poisson's ratio took 0.167 in the elastic section. The inelastic strain and damage constitutive relationship are demonstrated in equations (10) and (11) $[22,23]$ :

$$
\begin{aligned}
\mathcal{E}_{c, \text { in }} & =\frac{\varepsilon-\sigma}{E_{0}}, \\
\sigma & =(1-d) D_{0}:\left(\varepsilon-\varepsilon^{\mathrm{pl}}\right)=D:\left(\varepsilon-\varepsilon^{\mathrm{pl}}\right),
\end{aligned}
$$

where $E_{0}$ means the initial modulus of elasticity, $D_{0}$ is the initial elastic stiffness, $D$ symbols the degraded elastic stiffness, and $d$ is the damaging factor variable within the domain of 0 and 1 .

The uniaxial tension constitutive relation defined the peak stress $f_{\mathrm{t}}$ as $0.35 \mathrm{f}_{\mathrm{cu}}{ }^{0.55}$ and the softening section when the strain exceeds the ultimate strain $\varepsilon_{\mathrm{cu}}$. Meanwhile, the ultimate tensile strain and the corresponding residual stress in the tension-softening section of concrete have a great influence on the convergence of the calculation. The residual stress is thus defined as $0.13 f_{\mathrm{t}}$. Other related parameters are selected according to the measured values. The plastic nonlinear model is difficult to converge in the calculation. Considering that plastic deformation hardly occurs in the noncontact parts (concrete and embedded part), this area post minor impact towards test results. Therefore, the noncontact region is set as linear elastic material, and the contact part between concrete and embedded parts is defined as plastic material.

5.1.2. Interaction and Boundary Conditions. The binding constraints were established at the contact areas between the steel plate and the embedded parts. To facilitate the loading, a reference point was set on the upper surface of the steel plate followed by a kinematic coupling procedure. To coincide with the test results, some surface-tosurface contact pairs were set. Specifically, the steel plate with larger stiffness was set as the main surface and the concrete part was set as the slave surface. Moreover, the finite slip formula was utilized to define the finite element contact because the relative displacement between the embedded parts and the concrete may be arbitrary. The tangential and normal behaviors were mainly considered in the contact properties and the Coulomb friction was adopted in the friction model and the friction coefficient was 0.4 .

The model was placed on the loading table of the press with a clamp on the opposite side of the embedded part. The load was applied smoothly on the bolt to transfer the force to the embedded part. According to the experimental setting, three degrees-of-freedom constraints were applied to the concrete bottom and the displacement constraints were utilized for the steel plate.

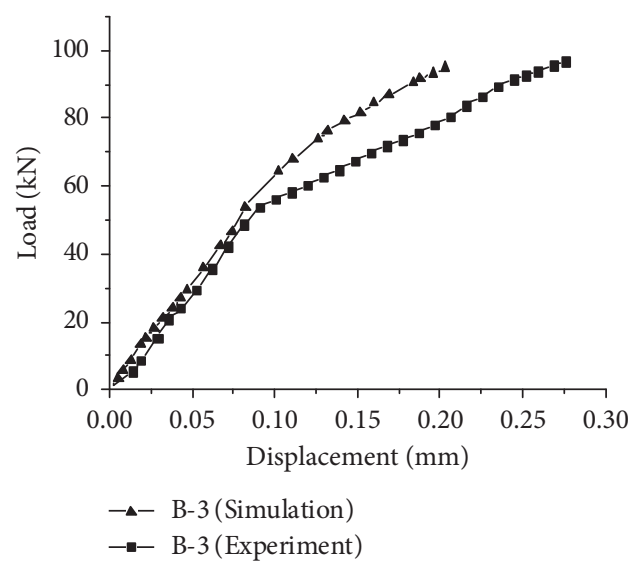

FIgURE 6: Comparison diagram of displacement load curve of B-3.

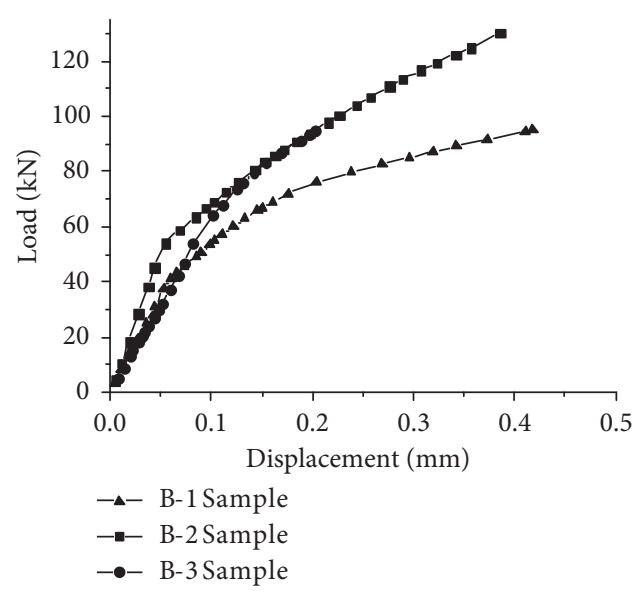

FIGURE 7: Simulated displacement load curve of three specimens.

5.1.3. Mesh Generation. In this paper, the 8-node hexahedron reduction integral entity element C3D8R was used in the plastic nonlinearity analysis. The embedded component was in $8 \mathrm{~mm}$ mesh size and the concrete unit was $30 \mathrm{~mm}$; the contact interface unit was in $7 \mathrm{~mm}$.

5.2. Finite Element Analysis Results. Figure 6 is the comparison of displacement load curve measured in the experiment and simulated by the finite element method. The experimental results of the embedded parts were in close agreement with the finite element analysis results. The displacement load-curve comparison obtained by finite element simulation is shown in Figure 7. It can be seen that the groove embedded parts have obvious elastic and plastic stages and are verified with the mechanical bearing capacity in the experiments.

Figure 8 demonstrates the concrete stress cloud diagram for the simulated B group specimens. The stress distribution on the upper surface in the finite element analysis was consistent with the damaged area of the concrete vertebral surface in experiments. When the embedded parts were subjected to bending and shearing force, the T-bolt would be pulled on the upper side, and we exert relatively large 

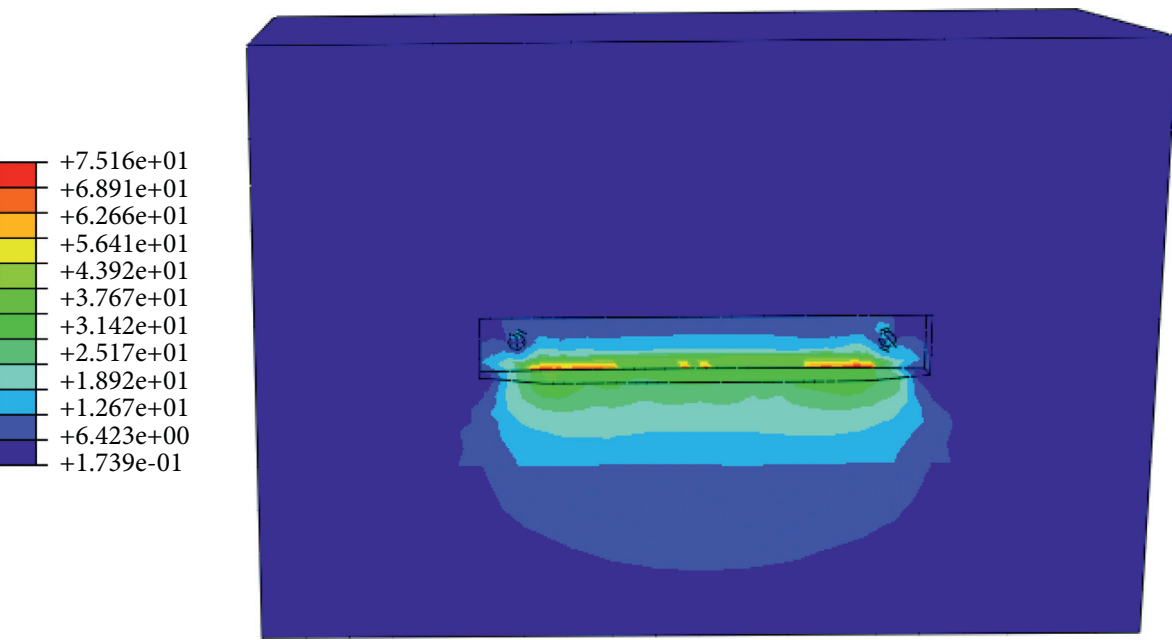

(a)
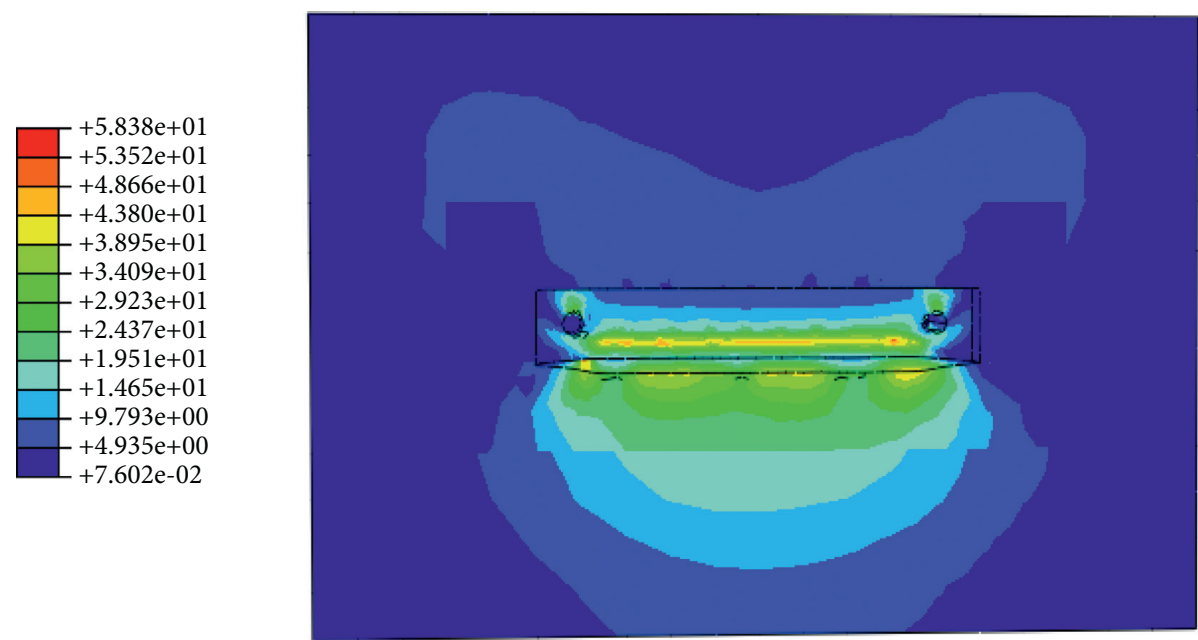

(b)
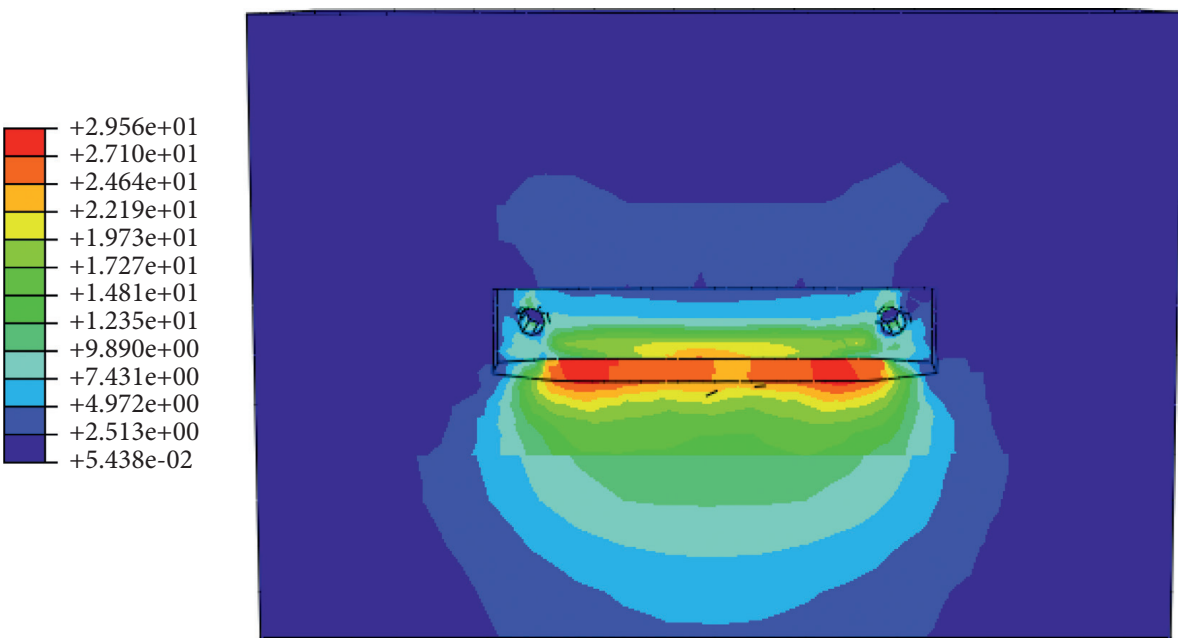

(c)

FIgURE 8: Concrete stress cloud diagram. (a) B-1, (b) B-2, and (c) B-3 (unit: MPa). 


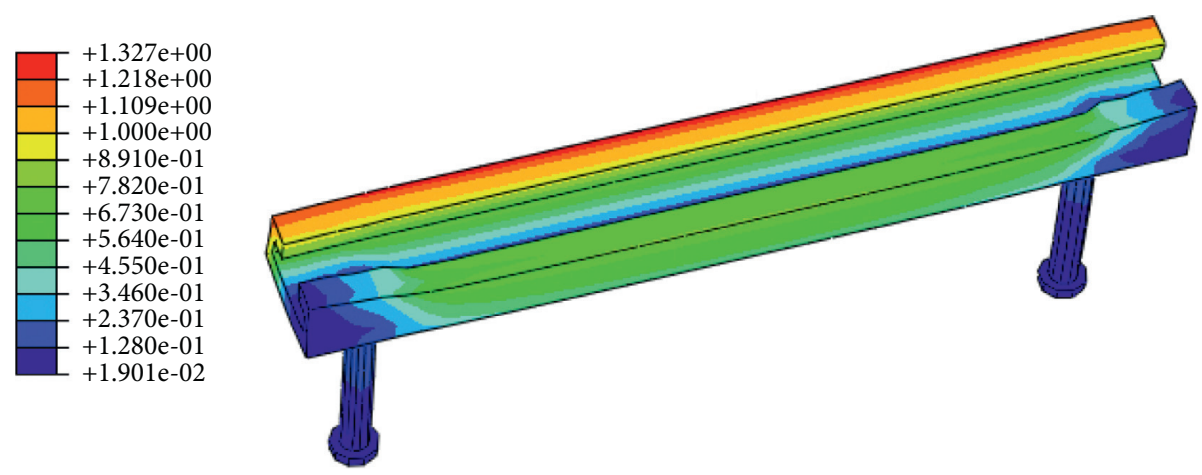

(a)
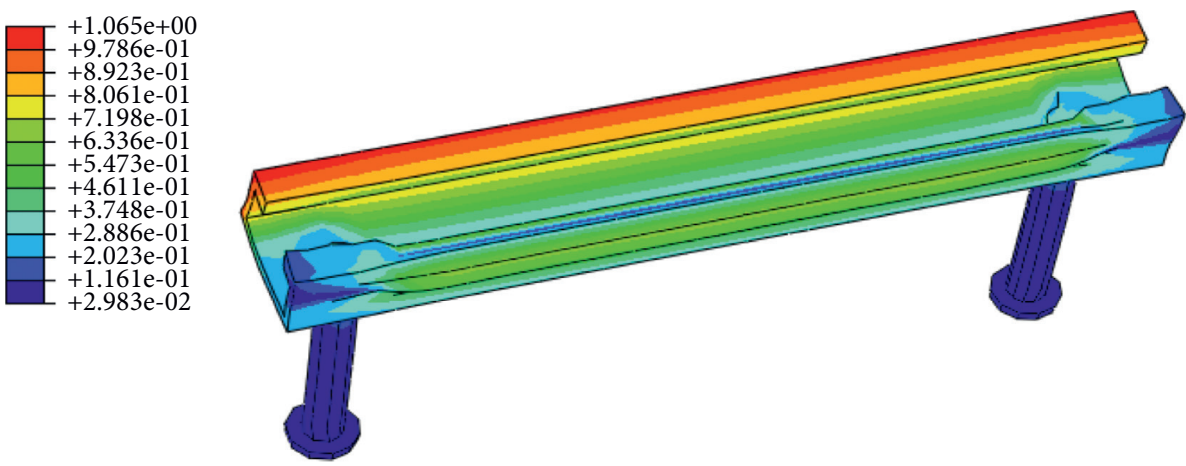

(b)
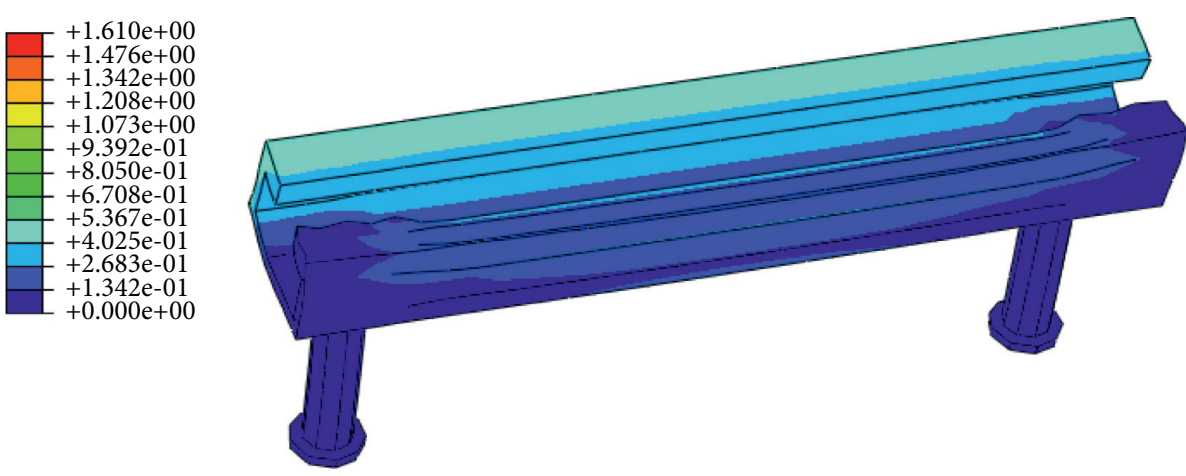

(c)

Figure 9: The embedded parts deformation diagram for (a) B-1, (b) B-2, and (c) B-3 (unit: mm).

compressive pressure on the lower side of the channel. When the displacement occurred upon T-bolt, the anchor leg in concrete would be pulled out slowly. Thereby, the punching effect upon the interaction between the anchor leg end and the concrete would increase. According to the stress cloud diagrams, the obvious stress concentration phenomenon was found at the interfaces for all three specimens, which was in agreement with the vertebral destruction caused by concrete in the mechanical experiments.

Figure 9 shows the deformation diagrams for the groove embedded parts' reinforced concretes. The displacement load-curve comparison figure obtained by finite element simulation is shown in Figure 10. From the listed figures, the maximum stresses for the simulated samples occurred at the bolt-channel steel interface and the anchor leg end. For the B-1 sample, the maximum stress reached $272.8 \mathrm{MPa}$ and was mainly at the connection between T-type bolts and groove steel. The groove-type embedded part was still in an elastic state, while the maximum stress of concrete stood at $75.16 \mathrm{MPa}$ at the end of the anchor leg, exceeding the compressive ultimate limit. The B-2 sample obtains the maximum stress of $268 \mathrm{MPa}$ also at the connection surface between T-type bolts and groove steel. Meanwhile, the groove-type embedded parts have not fully kept the plastic state, but the concrete's maximum stress $(58.38 \mathrm{MPa})$ has already reached the compressive limit at the end of anchor legs. For the B-3 specimen, the HALFEN groove's peak stress was simulated as $281.8 \mathrm{MPa}$ at the connection part between channel steel and T-type bolts. Simultaneously, both the embedded parts and the concrete component did not exceed the plastic level threshold. The works can lay the foundation for future artificial intelligence optimization works. 


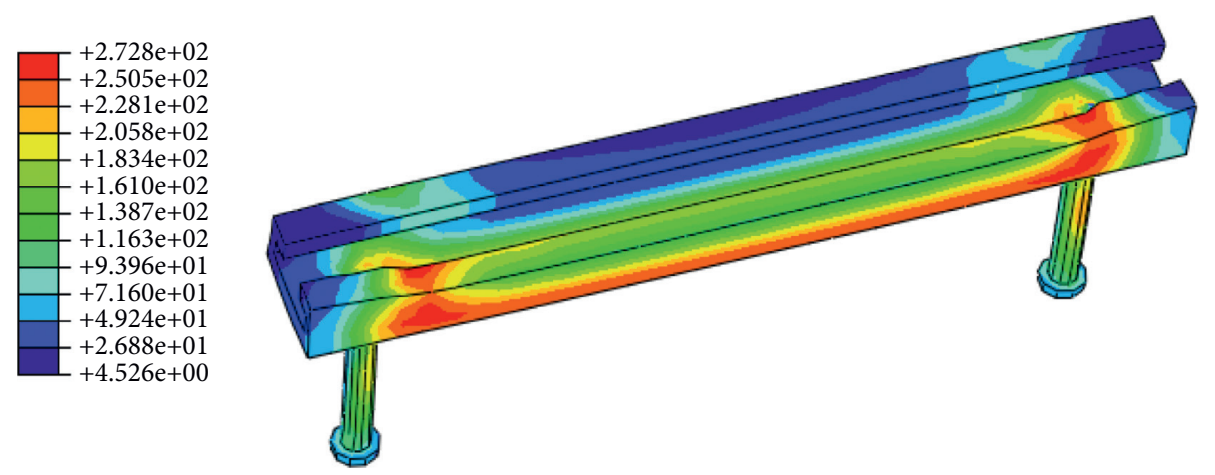

(a)
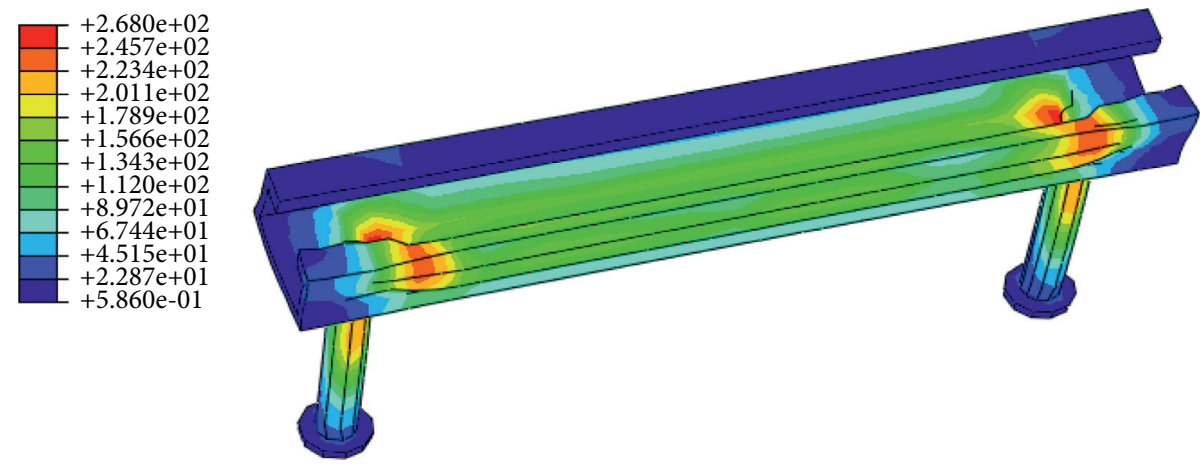

(b)
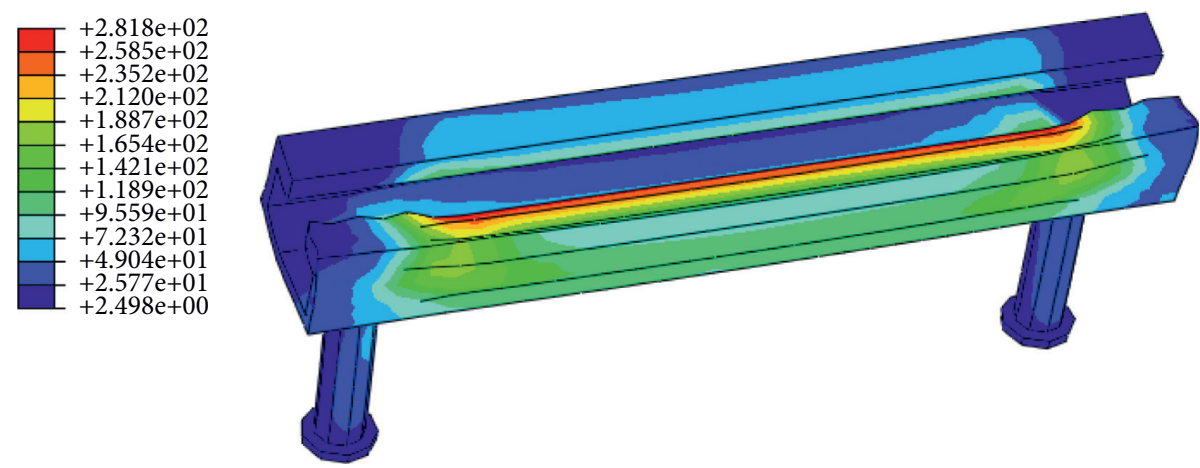

(c)

Figure 10: The embedded stress diagram for (a) B-1, (b) B-2, and (c) B-3 (unit: MPa).

\section{Conclusion}

The purpose of the study was to investigate the reliability of sustainable plate embedded parts and grooved embedded parts' reinforced concrete structures. The main conclusions of the study can be summarized as follows:

(1) The self-developed Zn-A1-Mg-RE coating enhances the sustainability performance of the embedded parts, which benefits the whole concrete structure of a longer service life span. The plate embedded parts supplied higher bearing capacity and the HALFEN groove with $50 \mathrm{~mm}$ width and $30 \mathrm{~mm}$ height was the most suitable category in reinforcing works.
(2) The theoretical calculation of failure bearing capacity for both plate embedded parts and grooved embedded parts reinforced concrete structures was consistent with the experimental results. The failure modes for embedded parts' reinforced concrete structures were the destruction of concrete vertebrae with obvious cracks.

(3) Based on the finite element analysis of three groove embedded specimens, the concrete at the end of the anchor leg had an obvious stress concentration phenomenon, which was consistent with the phenomenon of vertebral body destruction caused by concrete in the experiment. The finite element simulations were in according to the experimental results and theoretical calculation results. 


\section{Data Availability}

All data used to support the study are included within the article.

\section{Conflicts of Interest}

The authors declare that they have no conflicts of interest.

\section{Acknowledgments}

This research was supported by the projects of "the Fundamental Research Funds for the Central Universities (2020ZDPY0221 and 2021QN1003)," "National Natural Science Foundation of China (52104106 and 52174089)" and Basic Research Program of Xuzhou (KC21017).

\section{References}

[1] S. O. Hong and C. J. Aldrete, "Simple method for upgrading an existing reinforced-concrete structure," Practice Periodical on Structural Design and Construction, vol. 1, no. 1, pp. 47-50, 1996.

[2] K. M. A. Hossain, M. Lachemi, M. Sammour, and M. Sonebi, "Influence of polyvinyl alcohol, steel, and hybrid fibers on fresh and rheological properties of self-consolidating concrete," Journal of Materials in Civil Engineering, vol. 24, no. 9, pp. 1211-1220, 2012.

[3] D. Hu and K. Ma, "A study on reliability of reinforced concrete structure," Journal of Building Structures, vol. 14, 1987.

[4] R. Pucinotti, "Reinforced concrete structure: non destructive in situ strength assessment of concrete," Construction and Building Materials, vol. 75, no. 75, pp. 331-341, 2015.

[5] L. Hu, Y. Wang, P. Feng, H. Wang, and H. Qiang, "Debonding development in cracked steel plates strengthened by CFRP laminates under fatigue loading: experimental and boundary element method analysis," Thin-Walled Structures, vol. 166, Article ID 108038, 2021.

[6] L. Hu and P. Feng, "Prestressed CFRP-reinforced steel columns under axial and eccentric compression," Composite Structures, vol. 268, Article ID 113940, 2021.

[7] L. Hu, P. Feng, and X.-L. Zhao, "Fatigue design of CFRP strengthened steel members," Thin-Walled Structures, vol. 119, pp. 482-498, 2017.

[8] F. Aslani and S. Nejadi, "Bond behavior of reinforcement in conventional and self-compacting concrete," Advances in Structural Engineering, vol. 15, no. 12, pp. 2033-2051, 2012.

[9] L. Gerola, "Connecting horizontal panels and vertical panels in prefabricated buildings," Google Patents, 1972.

[10] L. L. Hu, X. L. Zhao, and P. Feng, "Fatigue behavior of cracked high-strength steel plates strengthened by CFRP sheets," Journal of Composites for Construction, vol. 20, no. 6, Article ID 04016043, 2016.

[11] R. Böllinghaus, "Transport anchor for embedding in prefabricated reinforced concrete parts," Google Patents, 2002.

[12] R. K. Stout, "Method for making cast-in-place concrete structures," Google Patents, 1975.

[13] R. K. Stout, "Void creating device to be embedded in a concrete structure," Google Patents, 1975.

[14] B. Zoubek, M. Fischinger, and T. Isakovic, "Estimation of the cyclic capacity of beam-to-column dowel connections in precast industrial buildings," Bulletin of Earthquake Engineering, vol. 13, no. 7, pp. 1-24, 2014.

[15] D. Standards, Design of Fastenings for Use in Concrete - Part 43: Anchor Channels, 1992.

[16] X. Liu, M. A. Bradford, and A. Ataei, "Flexural performance of innovative sustainable composite steel-concrete beams," Engineering Structures, vol. 130, pp. 282-296, 2017.

[17] P. K. Sarker, "Bond strength of reinforcing steel embedded in fly ash-based geopolymer concrete," Materials and Structures, vol. 44, no. 5, pp. 1021-1030, 2011.

[18] P. Valeri, M. F. Ruiz, and A. Muttoni, "Modelling of textile reinforced concrete in bending and shear with elastic-cracked stress fields," Engineering Structures, vol. 215, Article ID 110664, 2020.

[19] B. Han, Y. Wang, S. Dong et al., "Smart concretes and structures: a review," Journal of Intelligent Material Systems and Structures, vol. 26, no. 11, pp. 1303-1345, 2015.

[20] K. Hibbitt, Sorensen. ABAQUS/Standard User Subroutines Reference Manual, Sorensen, Inc, Chicago, IL, USA, 2002.

[21] A. Jawdhari and I. Harik, "Finite element analysis of RC beams strengthened in flexure with CFRP rod panels," Construction and Building Materials, vol. 163, pp. 751-766, 2018.

[22] W. Demin and H. Fukang, "Investigation for plastic damage constitutive models of the concrete material," Procedia engineering, vol. 210, pp. 71-78, 2017.

[23] T. Supaviriyakit, P. Pornpongsaroj, and A. Pimanmas, "Finite element analysis of FRP-strengthened RC beams," Songklanakarin Journal of Science and Technology, vol. 26, no. 4, pp. 497-507, 2004. 